\title{
Refractive Changes After YAG laser Capsulotomy in Pseudophakic Patients
}

\section{Eman Saeed Fathy Elsayed*, Hazem Effat Haroun, Ahmed Taha Gouda}

Ophthalmology department, Faculty of Medicine, Beni-Suef University, Egypt.

Email: eman_asi91@yahoo.com

tel: 01009743244

\section{Abstract :}

Background: The aim of our study was to evaluate the effect of $\mathrm{Nd}$ :YAG laser posterior capsulotomy on patient's refractive status .

Methods: a retrospective study that involved 30 eyes (of 30 patient) treated with Nd:YAG laser capsulotomy due to posterior capsular opacification after uncomplicated phacoemulsification surgery and intraocular lens implantation. Complete ocular examinations were done for all patients before and after YAG capsulotomy. The best corrected visual acuity, sphere and cylinder were obtained before capsulotomy, one week and one month after capsulotomy and changes were investigated. Data was analyzed statistically.

Results: It was found that the mean refractive sphere shift towards myopic changing, The mean refractive cylinder changes towards hyperopic shift, there were no statistical significance of any change in axis of the cylinder .

Conclusion: Statistical significant improvement in BCVA after Nd:YAG laser capsulotomy, so $\mathrm{Nd}$ :YAG is an effective instrument used in non-invasive treatment of posterior capsular opacification

Keywords : Refractive changes, YAG laser capsulotomy, pseudophakic patients .

Receive Date : 25/2/2021

Accept Date: 5/3/2021

Publish Date : $1 / 4 / 2021$

\section{Introduction}

Posterior capsular opacification (PCO) is the most common long-term complication of cataract surgery in both phacoemulsification and extracapsular cataract extraction (ECCE). The incidences of PCO were $11.8 \%$ at 1 year, $20.7 \%$ at 3 years, and $28.4 \%$ at 5 years after surgery (1).

It results in decreased visual acuity, reduced contrast sensitivity, glare and monocular diplopia. The proliferation of the lens epithelial cell remnants in the intracapsular area plays an essential role in the pathogenesis of PCO. Continuous curvilinear capsulorhexis, successful hydrodissection, excellent removal of cortex and lenticular epithelial cells, in-the bag IOL placement and using a single-piece, acrylic sharp edges IOLs can be listed among the factors in the prevention of PCO. Anti-metabolites such as 5-fluorouracil and mitomycin $\mathrm{C}$ may also be used intraoperatively for this purpose. Fortunately, the overall incidence of PCO and the incidence of neodymium-yttrium-aluminum-garnet (Nd: YAG) laser posterior capsulotomy has decreased from $50 \%$ in to less than $10 \%$ today (2).

Some patients experience significant vision complications including decreased visual acuity, glare, and contrast sensitivity, which often require further treatment. Currently, the standard 
treatment for PCO is Nd:YAG laser posterior capsulotomy, which has a success rate of more than 95\% (3) . It is the preferred treatment method in PCO with its economical, rapid and non-invasive aspects (4) . Reported complications of Nd:YAG laser posterior capsulotomy include elevated intraocular pressure, iritis, corneal damage, intraocular lens (IOL) damage, cystoid macular edema, disruption of the anterior hyaloid surface, increased risk of retinal detachment, and IOL movement or dislocation .In some patients, a refraction change was noticed after Nd:YAG laser posterior capsulotomy, but proving this remains difficult . Petesern et al reported four cases of posterior silicone haptic IOL dislocation after Nd: YAG laser posterior capsulotomy at a mean of 16 months after treatment. Several studies have demonstrated IOL movement after laser treatment in a different manner; Findl et al reported backward IOL movement and hyperopic shift (5). Any significant change in IOL position can lead to a change in the patient's refractive status, which will therefore require corrective lens prescriptions

\section{Purpose:}

To evaluate the effect of Nd:YAG laser posterior capsulotomy on patient's refractive status .

\section{Patients and methods:}

Our study was conducted at Beni Suef University, involving 30 patient aged 40-70 yrs. between March and August 2019 .

\section{Inclusion criteria:}

Clear cornea in patients aged 40_70 years old performed cataract surgery.

\section{Exclusion criteria:}

Ocular and systemic diseases affect the eye, high IOP ,previous ocular surgery, Corneal opacities or dystrophies.

All patients were subjected to: All participants underwent ophthalmological examination.

- vision assessment using the LogMAR chart

- Autoref before YAG laser and after 1 week ,1 month of procedure.

- Anterior segment examination using a slit lamp

- Fundus examination using direct and indirect ophthalmoscopy

- Intraocular pressure

-The posterior capsulotomies will be performed in a single session with a Nd:YAG laser .

\section{Statistical methodology}

The collected data will be tabulated, coded and analyzed using SPSS program for windows 7 , version 23 , continuous variables will be presented as mean values -/+ standard deviation (SD), and categorical variables

will be presented as percentages. Changes in patient refractions in terms of spherical and cylindrical powers were compared separately. Analyses of cylindrical power excluding the axis were performed.

\section{Published by : N I L E S}


Comparison amongst data will be done using suitable P-value $<0.05$ will be considered as statistically significant.

\section{Results}

The results were BCVA and refractive changes prior to Nd:YAG laser posterior capsulotomy and 1 week , 1 month after the procedure. In Beni- suef University Hospital with a total of 30 eyes .All patients were aged 40 - 70 years old.

Table (1): Distribution according age groups.

\begin{tabular}{|l|l|l|}
\hline \multicolumn{2}{|c|}{} & No. $=\mathbf{3 0}$ \\
\hline \multirow{3}{*}{ Age } & Mean \pm SD & $61.27 \pm 7.03$ \\
& Range & $40-70$ \\
\hline \multirow{3}{*}{ Sex } & Female & $16(53.3 \%)$ \\
\hline \multirow{2}{*}{ Side } & Male & $14(46.7 \%)$ \\
\hline
\end{tabular}

Table (2): Refractive changes prior to Nd: YAG laser posterior capsulotomy and 1 week , 1 month after the procedure.

\begin{tabular}{|c|c|c|c|c|c|c|c|}
\hline & & Pre refraction & $\begin{array}{l}\text { Post } 1 \text { week } \\
\text { refraction }\end{array}$ & $\begin{array}{l}\text { Post } 1 \text { month } \\
\text { refraction }\end{array}$ & $\begin{array}{l}\text { Test } \\
\text { value }\end{array}$ & P-value & Sig. \\
\hline \multirow[t]{2}{*}{ Sphere } & Mean \pm SD & $0.70 \pm 2.91$ & $-0.07 \pm 2.35$ & $-0.27 \pm 2.16$ & \multirow[t]{2}{*}{21.509} & \multirow[t]{2}{*}{0.001} & \multirow[t]{2}{*}{ HS } \\
\hline & Range & $-6-10$ & $-6-8$ & $-6-8$ & & & \\
\hline \multirow[t]{2}{*}{ Cylinder } & Mean \pm SD & $-2.57 \pm 1.19$ & $-1.77 \pm 1.04$ & $-1.57 \pm 1.01$ & \multirow{2}{*}{34.794} & \multirow{2}{*}{0.001} & \multirow[t]{2}{*}{ HS } \\
\hline & Range & $-6--1$ & $-4-0$ & $-4-0$ & & & \\
\hline \multirow[t]{2}{*}{ Axis } & Mean \pm SD & $74.07 \pm 41.87$ & $81.13 \pm 42.68$ & $84.37 \pm 42.15$ & \multirow[t]{2}{*}{5.707} & \multirow[t]{2}{*}{0.058} & \multirow[t]{2}{*}{ NS } \\
\hline & Range & $5-171$ & $7-176$ & $4-175$ & & & \\
\hline
\end{tabular}

P-value >0.05: Non significant (NS); P-value <0.05: Significant (S); P-value< 0.01: highly significant (HS)

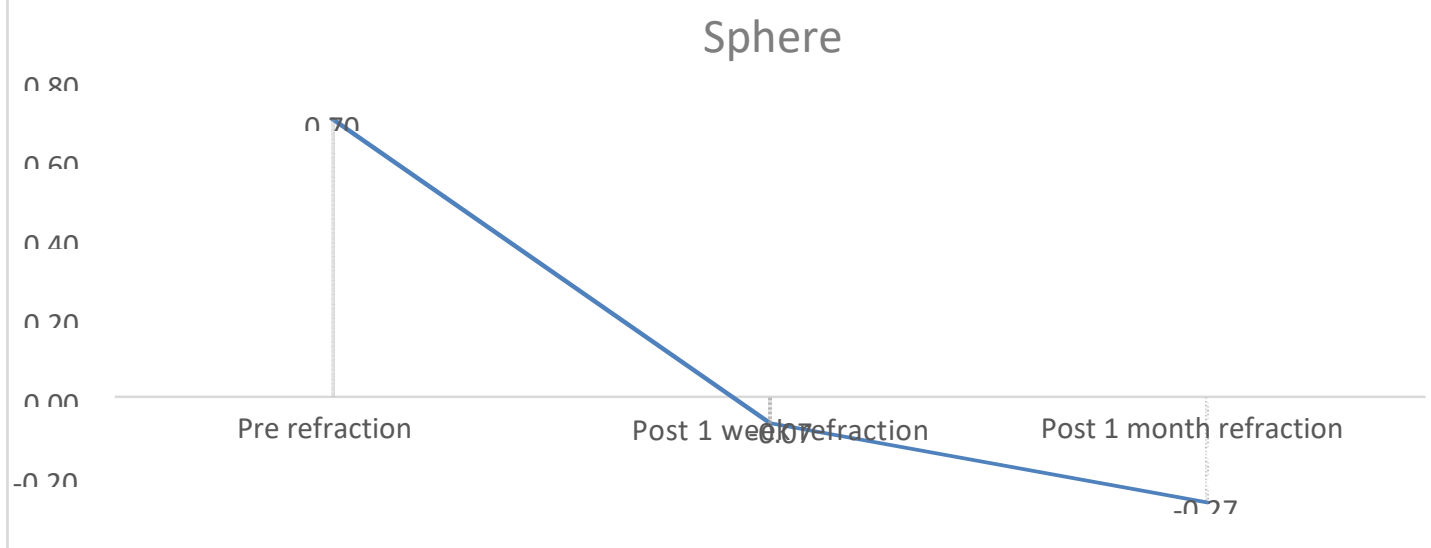

Figure (1) show changes in the Refractive Sphere prior to Nd:YAG laser posterior capsulotomy and 1 week,1 month after the procedure showing shift towards myopia. 
The figure illustrate refractive Sphere mean changed from $0.70 \pm 2.91$ (SD) before capsulotomy to be $-0.07 \pm 2.35$ (SD) after 1 week capsulotomy and to $-0.27 \pm 2.16$ (SD) after 1 month capsulotomy ; that show a highly significant change toward myopic shift where the $p$ value was 0.001 .

\section{Cylinder}

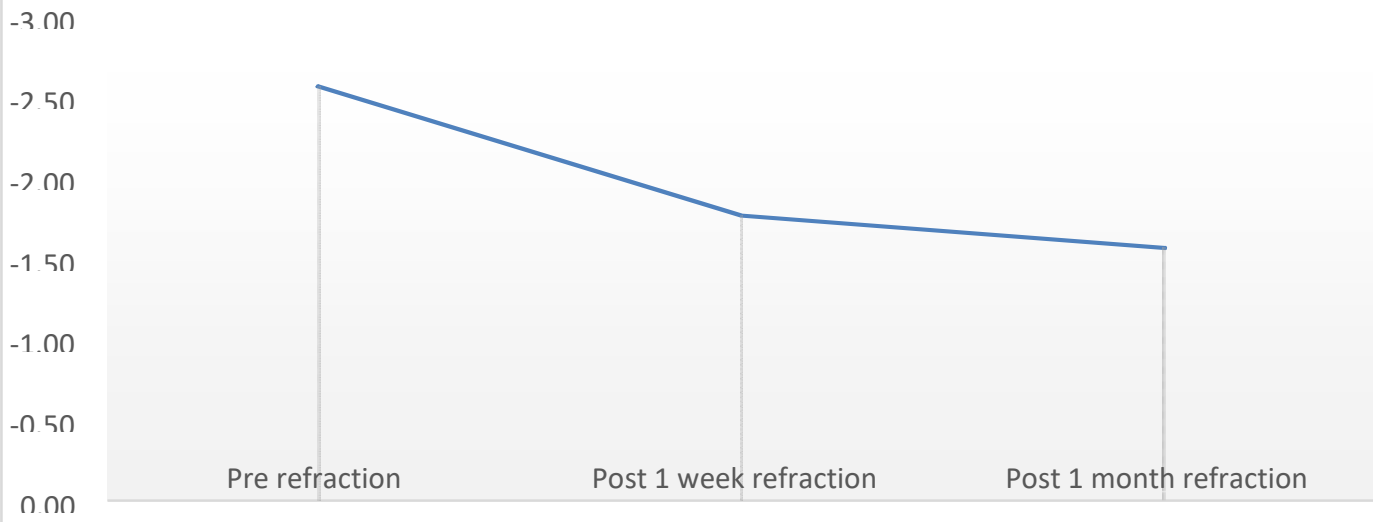

Figure (2) Changes in the Refractive Cylinder prior to Nd:YAG laser posterior capsulotomy and 1 week, 1 month after the procedure showing shift towards hyperopia.

The figure illustrate mean refractive cylinder changed from $-2.57 \pm 1.19$ (SD) before capsulotomy to be $-1.77 \pm 1.04$ (SD) after 1 week capsulotomy and to $-1.57 \pm 1.01$ (SD) after 1 month capsulotomy, that show a highly significant refractive cylinder changes towards hyperopic shift where the $\mathrm{p}$ value was 0.001

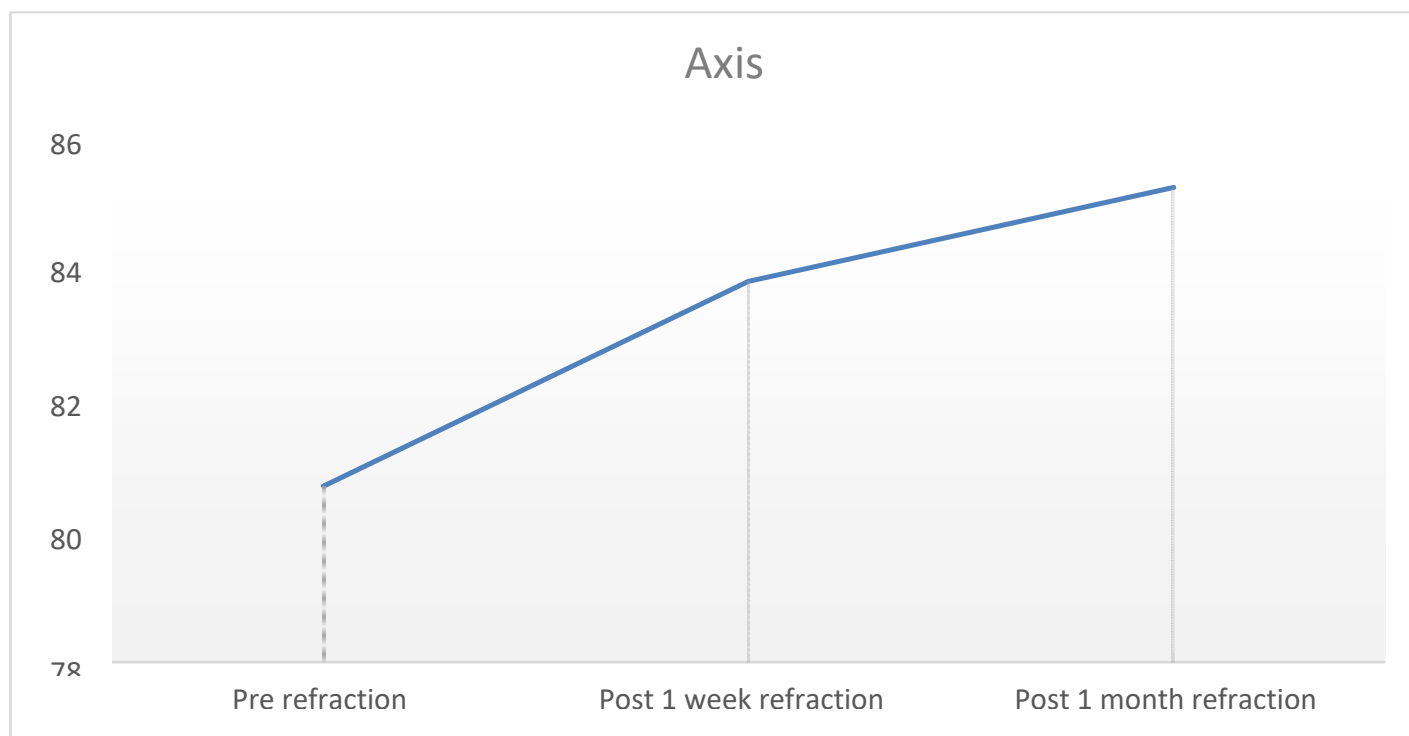

Figure (3) Changes in the Axis of Refractive Cylinder prior to Nd:YAG laser posterior capsulotomy and 1 week, 1 month after the procedure showing no significant changes .

The figure illustrate mean Axis of Refractive Cylinder changed from $74.07 \pm 41.87$ 
(SD) before capsulotomy to $81.13 \pm 42.68$ (SD) after 1 week capsulotomy and to 84.37 \pm 42.15 after 1 month of capsulotomy, that show no significant changes in axis of refractive cylinder where the $\mathrm{p}$ value was 0.045 .

Table (3): changes of BCVA before and after capsulotomy and $P$ value .

\begin{tabular}{|l|l|l|}
\hline \multicolumn{2}{|c|}{ BCVA } & No. $=\mathbf{3 0}$ \\
\hline \multirow{2}{*}{ Pre } & Mean \pm SD & $0.10 \pm 0.31$ \\
& Range & $0-1$ \\
\hline \multirow{2}{*}{ Post } & Mean \pm SD & $0.50 \pm 0.51$ \\
\hline \multirow{2}{*}{ Mean difference } & Range & $0-1$ \\
& Mean \pm SD & $0.07 \pm 0.25$ \\
& Range & $0-1$ \\
\hline Willcoxon Rank test & \\
p-value & $\mathbf{- 3 . 2 0 7}$ \\
\hline
\end{tabular}

BCVA = Best Corrected Visual Acuity

Pre BCVA= Precapsulotomy BCVA

Post BCVA = Postcapsulotomy BCVA

The table illustrates BCVA changed where the mean BCVA prior to capsulotomy was $0.10 \pm$ $0.31(\mathrm{SD})$ and altered to $0.50 \pm 0.51(\mathrm{SD})$ after capsulotomy. $\mathrm{P}$ value was 0.001 which indicate statistical significance improvement in BCVA after capsulotomy.

\section{Discussion:}

PCO remains the most common long-term complication after cataract Surgery (6). The incidence of PCO was recorded to be $20.7 \%$ at two years and $28.5 \%$ at 5 years after cataract surgery . At present, Nd:YAG laser is the standard treatment for correction of visual loss caused by capsular opacification and remains the gold standard for the treatment of PCO. This procedure is reliable but it has several complications such as IOP changes, IOL damage and dislocation, iridocyclitis, vitreous hemorrhage and vitritis, retinal detachment,macular edema. Nd:YAG laser capsulotomy may make changes in refraction. There is no consensus about the changes of refractive status. Some authors found that large capsulotomy size may cause IOL posteriorly movement result in hyperopic shift .On the other hand, some authors declared that Nd:YAG laser capsulotomy does not affect spherical equivalent (SE) (7) .

In our study we included thirty eyes of 30 pseudophakic patients; the mean age for these patients at the procedure was 61.27 years \pm 7.03 (SD). 14 male patients with percentage of $46.70 \%$ and 16 female patients with percentage of $53.3 \%$,of overall number of patients. 
Our study were similar with other studies their results found a significant myopic shift due to decrease in AC depth. These results could be explained from their methodology as the AC depth was measured using a contact A-scan ultrasound while the intraocular pressure medically reduced. They recommended to prescribe the optimal corrective lenses after 1 month of the YAG laser capsulotomy .

Other studies showed nearly similar results compared to ours our results reported that there was a significant change of refractive cylinder towards hyperopia where mean refractive cylinder changed from $0.75 \pm 0.34$ (SD) before capsulotomy to be $-0.38 \pm 0.28$ (SD) after capsulotomy where $\mathrm{P}$ value was 0.039 .

Our results were in agreement with other studies who reported that there's no statistically significant change in the axis of the refractive cylinder where the mean was 85.16 \pm $50.89(\mathrm{SD})$ to be $91.97 \pm 53.86(\mathrm{SD})$ with a $\mathrm{P}$ value of 0.053 .

As regards BCVA in our study we found that statistical significance improvement in BCVA after capsulotomy changed where the mean BCVA prior to capsulotomy was $0.10 \pm 0.31$ (SD) and altered to $0.50 \pm 0.51(\mathrm{SD})$ after capsulotomy. $\mathrm{P}$ value was 0.001 .

These results were similar with those reported by Berkay et al, who reported statistically significant in improvement in BCVA at 1 week and 1 month was in both groups $(p<0,001)$ in Fifty-six eyes of 56 pseudophakic patients with PCO who underwent Nd:YAG laser posterior capsulotomy . (8)

\section{Conclusion}

Our study of the effect Nd YAG laser of PCO after cataract surgery encluded Thirty eye of 30 pseudophakic patients who presented to the outpatient clinic and diagnosed as having PCO after a previous cataract extraction and IOL implantation concludes that there is significant improvement in Visual Acuity BCVA after Nd YAG laser capsulotomy. There is also change in the refractive sphere towards a myopic shift which is significant after the YAG laser capsulotomy, and a significant change in the Refractive Cylinder towards a hyperopic shift, while there is no significant change in the axis of cylinder.

\section{Summary:}

YAG laser capsulotomy is standard treatment for PCO and has been found to be safe and effective improvement in visual acuity after Nd:YAG laser capsulotomy in patients with significant PCO improvements in glare and contrast sensitivity may also be important outcome measures for many patients. According to results recommended to prescribe the optimal corrective lenses after 1 month of the yag laser capsulotomy than before to avoid potential refractive changes . 


\section{References:}

(1) - Chaumberg DA, Dana MR, Christen WG, Glynn RJ.: A systematic overview of the incidence of posterior capsule opacification. Ophthalmology. 1998;105(7):1213-1221.

(2) - Dholakia SA, Vasavada AR.: Intraoperative performance and longterm outcome of phacoemulsification in age-related cataract. Indian J. Ophthalmol. 2004 Dec;52(4):311.

(3) - Bhargava R. A review of posterior capsule opacification. Int J Ophthalmic Pathol. 2014;3:4.

(4) - Gore VS.: The study of complications of Nd-YAG laser capsulotomy. Int J Bioinform Res. 2012;4:265-68.

(5) - Findl O, Drexler W, Menapace R, et al. : Changes in intraocular lens position after neodymium: YAG capsulotomy. J Cataract Refract Surg.1999;25(5):659-662.

(6) - Aslam TM, Devlin H, Dhillon B.: Use of Nd:YAG laser capsulotomy. Surv Ophthalmol, 2003;48(6):594-612.

(7) - Chua CN, Gibson A, Kazakos DC.: Refractive changes following Nd:YAG capsulotomy. Eye (Lond). 2001;15(Pt 3):304-305.

(8) - Bhargava R. A review of posterior capsule opacification. Int J Ophthalmic Pathol. 2014;3:4 